\title{
Sex differences in pacing during half-marathon and marathon race
}

Cuk, Ivan ; Nikolaidis, Pantelis Theodoros ; Knechtle, Beat

\begin{abstract}
The main aim of the present study was to examine differences in pacing between half-marathon and marathon in men and women. A total of 17,525 finishers in the marathon ( $\mathrm{n}=4807$ men; $\mathrm{n}=1278$ women) and half-marathon race $(\mathrm{n}=7624$ men; $\mathrm{n}=3816$ women) in Vienna 2017 were considered. Their pacing was assessed through five race segments $(0-23.7 \%, 23.7-47.4 \%, 47.4-71.1 \%, 71.1-94.8 \%$ and $94.8-100 \%)$ of the race. Compared to marathon (where absolute average change of speed [ACS] was $5.46 \%$ and $4.12 \%$ in men and women, respectively), a more even pacing was observed in half-marathon in both sexes (ACS $=3.60 \%$ and $3.36 \%$ in men and women, respectively). The more even pacing in women previously observed in marathon races was verified in halfmarathon, too. However, the sex difference in pacing was smaller in half-marathon than in marathon. Since men and women endurance runners participate in both races, sport practitioners would have great benefit from these results since they could establish sex-based personalized race strategies and training programmes.
\end{abstract}

DOI: https://doi.org/10.1080/15438627.2019.1593835

Posted at the Zurich Open Repository and Archive, University of Zurich

ZORA URL: https://doi.org/10.5167/uzh-171197

Journal Article

Accepted Version

Originally published at:

Cuk, Ivan; Nikolaidis, Pantelis Theodoros; Knechtle, Beat (2020). Sex differences in pacing during half-marathon and marathon race. Research in Sports Medicine, 28(1):111-120.

DOI: https://doi.org/10.1080/15438627.2019.1593835 


\title{
Running head: Sex difference in pacing in marathon running
}

\author{
Ivan $\mathrm{Cuk}^{1}$, Pantelis Theodoros Nikolaidis ${ }^{2}$, Beat Knechtle $\mathrm{K}^{3,4}$
}
${ }^{1}$ Faculty of Physical Education and Sports Management, Singidunum University, Serbia ${ }^{2}$ Exercise Physiology Laboratory, Nikaia, Greece
${ }^{3}$ Institute of Primary Care, University of Zurich, Switzerland
${ }^{4}$ Medbase St. Gallen Am Vadianplatz, St. Gallen, Switzerland




\section{Abstract}

29 The main aim of the present study was to examine differences in pacing between half-marathon 30 and marathon in men and women. A total of 17,525 finishers in the marathon $(\mathrm{n}=4,807$ men;

$31 \mathrm{n}=1,278$ women) and half-marathon race ( $\mathrm{n}=7,624$ men; $\mathrm{n}=3816$ women) in Vienna 2017 were

32 considered.Their pacing was assessedthrough five race segments $(0-23.7 \%, 23.7-47.4 \%, 47.4-$

$3371.1 \%, 71.1-94.8 \%$ and $94.8-100 \%$ ) of the race. Compared to marathon, [where absolute average

34 change of speed (ACS) was $5.46 \%$ and $4.12 \%$ in men and women, respectively], a more even

35 pacing was observed in half-marathon in both sexes (ACS $=3.60 \%$ and $3.36 \%$ in men and

3

4

6

\section{7} women, respectively). The more even pacing in women previously observed in marathon races was verified in half-marathon, too. However, the sex difference in pacing was smaller in halfmarathon than in marathon. Since men and women endurance runners participate inboth races,sport practitioners would have great benefit from these results, since they could establish sex based personalized race strategies and training programs.

Keywords: aerobic capacity; endurance; gender; performance; running

.




\section{Introduction}

50 Pacing can be defined as moment-to-moment distribution ofpower output, speed or energetic

51 reserves during a particularsports event (Abbiss \& Laursen, 2008; Roelands, de Koning, Foster,

52 Hettinga, \&Meeusen, 2013). Along with training and proper diet, optimal pacing is a crucial

53 aspect of successful finish in long distance events, such as half-marathon, marathon or running

54 split of triathlon (Angus, 2014; Knechtle, Käch, Rosemann, \& Nikolaidis, 2019). Pacing in long

55 distance runningproves to be an important factorin both achieving record braking results in elite

56 runners as well as optimizing individual performance in recreational runners (Angus, 2014;

57 Santos-Lozano, Collado, Foster, Lucia, \&Garatachea, 2014).Moreover, optimal pacing is crucial

58 inpreventing unreasonably homeostatic disturbances during the racein addition to decreasing the

59 risk of musculoskeletal injuries (De Koning et al., 2011).

60 Numerous studies have been examining pacing in long distance running, primarily in ultra-

61 marathon (Lambert, Dugas, Kirkman, Mokone \&Waldeck, 2004;R.Hoffman, 2014) and

62 marathon (Deaner, Carter, Joyner, \& Hunter, 2015; Knechtle et al., 2016; Nikolaidis, Rosemann

$63 \&$ Knechtle, 2018).Several studies showed"positive pacing” profiles in these events, with

64 significant decrease in speed after approximately $30 \mathrm{~km}$ in marathon event (March,

65 Vanderburgh, Titlebaum, \& Hoops, 2011; Nikolaidis \& Knechtle, 2018).This can be attributed to

66 a muscle glycogen depletion (Roepstorff et al., 2002), also known as "hitting the wall",

67 neuromuscular fatigue (Millet, 2011) or even blood lactate accumulation, due to a fast start of the

68 race (Young, 2007), caused by a "risky" start (Deaner et al., 2015). However, only few studies

69 have ever examined pacing in half-marathon. Half-marathon events are becoming as attractive as

70 marathon events, withits popularity constantly increasing among the running community

71 (Hanley, 2016; Knechtle et al., 2016). Theyprove to be easier to complete,with less time needed 
72 for preparation, comparing to marathon. Information on pacing profiles for half-marathon

73 runners would be helpful in designing appropriate training programs, as well asracing strategies

74 in comparison to marathon.

75 The most recent studies (Nikolaidis, Cuk \& Knechtle, 2019) examined pacing in half-marathon, 76 in only one event, in a single year, while Hanley (2016) assessed pacing in merely elite runners.

77 Finally, Knechtle and Nikolaidis (2018) assessed pacing in half-marathon without comparing it

78 to the marathon pacing profiles. Considering that, pacing in half-marathon, as well as

79 comparison between marathon and half-marathon pacing profiles should require further

80 assessment.

81 Previous research showed that women had more stable pacing in long distance running than men

82 (March et al., 2011; Deaner et al., 2015; Nikolaidis et al., 2018). The sex difference in pacing

83 could beattributed to several physiological factors, such as lesser fatigability of women's skeletal

84 muscle(Hunter, 2014) or men's greater vulnerability to muscle glycogen depletion (Roepstorff et

85 al., 2002).Aforementioned sex differences could also have psychological background. Namely,

86 men often have a tendency towards fast start of the race(Deaner et al., 2015), thus increasing

87 blood lactate level or exhaust muscle glycogen levels earlier in the race, often called "hitting the

88 wall" (Coyle, 2007; Buman, Brewer, Cornelius, Van Raalte\&Petitpas, 2008). Therefore, the

89 further assessment of pacing in men and women, regarding both marathon and half-marathon

90 would be beneficial for sport scientists as well as coaches working with both marathon and half-

91 marathon runners. That way, they could establish sex based personalized race strategies and

92 training programs. 
93 Based on the disadvantages regarding previous studies, the first aim of this study was to establish

94 pacing profile in half-marathon event. Second aim of this study was toassess differences inpacing

95 profilesbetween marathon and half-marathon events, as well as, toassess pacing differences in

96 men and women, regarding both marathon and half-marathon events. Finally,establishing the

97 pacing strategy that works best for the men and women in both marathon and half-

98 marathon,corresponds to the third aim of this study.

99

100

101

102

103

104

105

106

107

108

109

110

111 


\section{Materials and Methods}

\section{Ethical approval}

115 This study was approved by the Institutional Review Board of Kanton St. Gallen, Switzerland, 116 with a waiver of the requirement for informed consent of the participants as the study involved

117 the analysis of publicly available data. The study was conducted in accordance with recognized 118 ethical standards according to the Declaration of Helsinki adopted in 1964 and revised in 2013.

Participants

121 For the purpose of this study, we have included official results and split times from2017 Vienna

122 City Marathon (www.vienna-marathon.com). A totalnumber of 6,085participants ofthe 2017

123 Vienna marathon ( $\mathrm{n}=4,807$ men; $\mathrm{n}=1,278$ women) and 11,440 participants of the 2017 Vienna

124 half-marathon ( $n=7,624$ men; $n=3816$ women) were included. Participants who did not finish

125 any of the races, or did not have recorded any of the split times were excluded from the

126 study.Both marathon and half-marathon were held on the same day on flat, officially certified

127 track, with elevation difference of50 m(ranging from $154-210 \mathrm{~m}$ ). Note that the half marathon

128 race was entirely contained within the marathon race. During the race day, weather was cloudy, 129 with temperature ranging from $7.8^{\circ} \mathrm{C}$ at 9 a.m. to $11.8^{\circ} \mathrm{C}$ at 2 p.m., without strong wind or excess 130 humidity.

\section{Data analysis}

133 In the first step of data analysis, we have calculated the average race speed for each participantin 134 half-marathon and marathon. Additionally, we have calculated average running speed in five 
135 race segments, for both marathon and half-marathon as previously reported by Nikolaidis, Cuk

136 and Knechtle (2019). Segment 1 included average running speed from 0 to $23.7 \%$ of both races.

137 That corresponds to 0 to $10 \mathrm{~km}$ segment for marathon and 0 to $5 \mathrm{~km}$ segment for half-marathon.

138 Furthermore, Segment 2 included average running speed from 23.7 to $47.4 \%$ of both races,

139 corresponding 10 to $20 \mathrm{~km}$ for marathon and 5 to $10 \mathrm{~km}$ for half marathon. Average running speed

140 from 47.4 to $71.1 \%$ of the races (i.e.,Segment 3) considered segments from 20 to $30 \mathrm{~km}$ in

141 marathon as well as 10 to $15 \mathrm{~km}$ segment for half-marathon. Segment 4 included average running

142 speed from 71.1 to $94.8 \%$ of both races. That corresponds to 30 to $40 \mathrm{~km}$ segment for marathon

143 and 15 to $20 \mathrm{~km}$ segment for half-marathon. Finally, endspurt or Segment 5 considered average

144 running speed from 94.8 to $100 \%$ of the race. In terms of race distances, that corresponds to the

145 segment from the $40^{\text {th }} \mathrm{km}$, to the race finish $(42.195 \mathrm{~km})$ in marathon as well as from the $20^{\text {th }} \mathrm{km}$,

146 to the race finish $(21.0975 \mathrm{~km})$ in half-marathon.

147

148 Consecutively, we have calculated the individual percentage of Average change in speed for 149 each of the five segments[ACSS = 100-(Average running race speed $/$ Average running speed for 150 segment $\mathrm{x}$ 100)].This methodology was previous utilized byNikolaidis, Cuk and Knechtle (2019) 151 and Santos-Lozano et al. (2014). Finally, we have calculated absolute average change ofspeed (in 152 percentage $)$, through the five race segments $[\mathrm{ACS}=(\mathrm{ACSS} 1+\mathrm{ACSS} 2+\mathrm{ACSS} 3+\mathrm{ACSS} 4+$

153 ACSS5) / 5], for each participant.Note that use of both positive and negative values could lower 154 the mean of the changes. To address this issue, we transformed all values to the absolute values 155 (i.e. only positive values). 


\section{Statistical analysis}

159 Prior to all statistical tests, descriptive statistics were calculated as a mean, standard deviation, minimum and maximum values. Data distribution normality was assessed by visual inspection of

161 histograms and QQ plots. Observed data showed rather normal distribution. In addition, a mixed

162 between-within analysis of variance (ANOVA) was performed for ACSS to test differences

163 between segments (i.e., Segments 1 to 5; within-subjects factor), race (i.e., marathon and half164 marathon; between-subjects factor) as well as their interaction (segment $\times$ race). To further 165 investigate pacing differences between marathon and half-marathon, we have performed 166 additionalmixed between-within ANOVAs for ACSS. First, two ANOVAs were performed to 167 assess differences between segments (i.e., Segments 1 to 5; within-subjects factor), race 168 (i.e., marathon and half-marathon; between-subjects factor) as well as their interaction (segment $\times$ 169 race) separately for men and women. Another two ANOVAs were performed to assess 170 differences between segments (i.e.,Segments 1 to 5; within-subjects factor), sex (i.e.,men and 171 women), as well as their interaction (segment $\times$ sex) separately for marathon and half-marathon.

172 Finally, one two way ANOVA was performed on ACS to assess differences between races

173 (i.e., marathon and half-marathon), sex (i.e., men and women) as well as their interaction (race $\times$ 174 sex). For all ANOVAs, post-hoc Bonferroni test was performed.Effects size was presented via 175 eta squared $\left(\mathrm{y}^{2}\right)$, where the values of.01, .06 and above .14 were considered small, medium, and 176 large, respectively (Cohen, 1988).Alpha level was set at $\mathrm{p}<0.05$.All statistical tests were 177 performed using Microsoft Office Excel 2007 (Microsoft Corporation, Redmond, WA, USA) 178 and SPSS 20 (IBM, Armonk, NY, USA). 


\section{Results}

The segments speed and entire race speed of participants were presented in Table 1.Regardless of their sex, both marathon and half marathon runners showed positive pacing pattern through the first four segments, with the characteristic endspurt (Table 1). Moreover, largest deviation of running speed was observed in marathon men, whereas the smallest deviation of running speed was observed in half-marathon women. Further examination of pace profiles was presented in Figures 1, 2, and 3.

In regards to marathon and half marathon runners of both sexes (Figure 1), significant main effects of segment $\left[\mathrm{F}(4,17520)=8736.9, \mathrm{y}^{2}=0.31, \mathrm{p}<0.01\right]$, race $\left[\mathrm{F}(4,17520)=48.3, \mathrm{y}^{2}<0.01\right.$, $\mathrm{p}<0.01]$ and segment $\times$ race interaction $\left[\mathrm{F}(4,17520)=837.6, \mathrm{y}^{2}=0.03, \mathrm{p}<0.01\right]$ were observed.On average, percentage of speed change was $2.19 \%$ greater in marathon than in halfmarathon $(\mathrm{p}<0.01)$. Moreover, in both marathon and half marathon runners, each segmentshowedsignificant differences in speed change than the other $(\mathrm{p}<0.01)$.

Regarding only men runners (Figure 2; panel a), significant main effects of segment $\left[\mathrm{F}(4,12421)=6524.3, \mathrm{y}^{2}=0.32, \mathrm{p}<0.01\right]$, race $[\mathrm{F}(4,12421)=119.1, \mathrm{y} 2<0.01, \mathrm{p}<0.01]$ and segment $\times$ race interaction $\left[F(4,12421)=951.5, \mathrm{y}^{2}=0.04, \mathrm{p}<0.01\right]$ were observed. On average, men marathon runners showed $2.49 \%$ greater speed change than men half marathon runners $(\mathrm{p}<$ 0.01).Significant main effects of segment $\left[F(4,5088)=1968.7, \mathrm{y}^{2} 2=0.27, \mathrm{p}<0.01\right]$, race $\left[\mathrm{F}(4,5088)=172.6, \mathrm{y}^{2}=0.01, \mathrm{p}<0.01\right]$ and segment $\times$ race interaction $\left[\mathrm{F}(4,5088)=73.8, \mathrm{y}^{2}=\right.$ $0.01, \mathrm{p}<0.01]$ were observed in women runners as well (Figure 2; panel b). On average, women marathon runners showed only $1.00 \%$ greater speed change than women half marathon runners $(\mathrm{p}<0.01)$. Regarding marathon runners $(\mathrm{x})$, significant main effects of segment $[\mathrm{F}(4$, $\left.6079)=2392.4, \mathrm{y}^{2}=0.27, \mathrm{p}<0.01\right], \operatorname{sex}\left[\mathrm{F}(4,6079)=87.7, \mathrm{y}^{2}<0.01, \mathrm{p}<0.01\right]$ and segment 
$202 \times$ sex interaction $\left[\mathrm{F}(4,6079)=108.6, \mathrm{y}^{2}=0.01, \mathrm{p}<0.01\right]$ were observed. Specifically, for each

203 segment, men showed greater speed change than women $(\mathrm{p}<0.01)$, which, on average

204 corresponds to $1.59 \%$.

205 Significant main effects of segment $\left[\mathrm{F}(4,11430)=3244.4, \mathrm{y}^{2}=0.21, \mathrm{p}<0.01\right], \operatorname{sex}[\mathrm{F}(4,11430)$

$\left.206=18.4, \mathrm{y}^{2}<0.01, \mathrm{p}<0.01\right]$ and segment $\times \operatorname{sex}$ interaction $\left[\mathrm{F}(4,11430)=18.7, \mathrm{y}^{2}<0.01, \mathrm{p}<0.01\right]$

207 were observed in half marathon as well (Figure 2; panels a and b). In contrast to our previous

208 findings, significant difference at alpha level 0.01 between men and women was found only in

209 segment 3 and 5 where men showed greater fluctuation of speed than women by $0.52 \%$ (on

210 average). In segment 1 and 4, women showed trivial, $0.25 \%$, speed change than men $(\mathrm{p}<0.05)$,

211 whereas in segment 2 , no significant differences was observed $(0.03 \%$ difference; $p=0.57)$.

212 Finally, in men and women runners in both marathon and half marathon, each segment each

213 segment showed significant differences inspeed change than the other $(\mathrm{p}<0.01)$.

214 Regarding ACS (Figure 3), significant main effects of race $\left[\mathrm{F}(3,17521)=464.8, \mathrm{y}^{2}=0.03, \mathrm{p}<\right.$

$2150.01]$, sex $\left[\mathrm{F}(3,17521)=124.9, \mathrm{y}^{2}=0.01, \mathrm{p}<0.01\right]$ and $\operatorname{racex}$ sex interaction $[\mathrm{F}(3,17521)=71.9$,

$\left.216 \mathrm{y}^{2}<0.01, \mathrm{p}<0.01\right]$ were observed. 


\section{Discussion}

224 In this paper, we establishedthe pacing profile in a half-marathon event, as a first aim of this

225 study. A second aim of this study was to assess differences in pacing profiles between marathon

226 and half-marathon running. And finally, we assessed pacing differences in men and women,

227 regarding both marathon and half-marathon running. Half-marathon runners establish a positive

228 pacing profile, i.e. constantly slowing down in speed, as the race progresses, with the

229 characteristic endspurt in the final 1.0975 meters. A similar pacing profile was established in

230 marathoners as well, however, changes in running speed werehigher in marathoners in regards to

231 half-marathoners. Finally, men marathon runners showed greater speed fluctuations than women,

232 whereas in half-marathon both men and women had rather similar pacing profiles.

\section{$233 \quad$ Half-marathon pacing}

234 Half-marathon runners appear to have positive pacing profile (Figure 1), with the endspurt in the

235 final segment of the race. Similar results were obtained in another half-marathon studyin elite

236 runners (Hanley, 2016). It appears that even elite runners had positive pacing profile in half-

237 marathon, however, larger sample of recreational runners, in our study, showed greater plunge in

238 speed between $15^{\text {th }}$ and $20^{\text {th }}$ kilometre. Moreover, elite runners from Hanley's study (2016)

239 showed endspurt faster than average race speed, whereas in our study, endspurt in half-marathon

240 runners was still $2.29 \%$ slower than average race speed (Figure 1). Coaches could use these

241 findings, for example, to advise novice runners to pay particular attention to pacing training in

242 half-marathon. Finally, the most recent study (Nikolaidis, Cuk \& Knechtle, 2019), also showed

243 positive pacing in half-marathon, however, with no endspurt. That can be attributed to the

244 specificity of the race; therefore, further research in this field is needed. 
246 Several studiesinvestigating pacing in marathoncomply with our findings (March et al., 2011;

247 Deaner et al., 2015; Nikolaidis \& Knechtle, 2017).However, very few studies havedirectly

248 compared pacing in marathon and half-marathon (Nikolaidis, Cuk \& Knechtle, 2019). When

249 compared to the marathon, similar pacing profile was established in half-marathon (i.e. positive

250 pacing with endspurt). However, fluctuations in speed were more even in half-marathon in

251 regards to the marathon.First segment in marathon was more than 5\% faster than the average

252 race speed, whereas half-marathon runners were less than $2 \%$ faster.Similar to that, in the fourth

253 segment, marathon runners showed greater loss of speed, followed by slower endspurt than half-

254 marathon runners. The knowledge of the near finish might motivate the runners to mobilize the

255 last reserves for end spurt (Nikolaidis \& Knechtle, 2018).However, a fast start of the marathon

256 runners can cause an additional fatigue induced in the fourth segment (Young, 2007), therefore,

257 slowing the end spurt. Consequently, we can argue that half-marathon runners were probably

258 less fatigued with more energy saved for the endspurt.

\section{Sex differences in pacing}

260 When sex differences were observed, women marathon runners showed less running variability

261 than men in the same event, which corresponds with previous studies (March et al., 2011; Deaner

262 et al., 2015; Nikolaidis et al., 2018).Observed sex differences have been previously attributed to

263 differences in physiology and decision making between women and men. In particular, men may

264 be more likely to adopt a "risky" pace, where an individual begins the race with a fast pace

265 (relative to their ability) thus increasing likelihood of slowing later (Deaner et al., 2015).

266 Moreover, some studies have reported that men tends to start fast, since they are more 
267 competitive than women (Ogles \& Masters, 2003).However, that was not the case in half-

268 marathon event, given that women had rather similar pacing profile comparing to men. We can

269 assume that physiological, rather than psychological factors can influence additional slowing in

270 marathon men (and not half-marathon men), such as, men muscle glycogen depletion (March et

271 al., 2011), better utilization of fat by women(Tarnopolsky, 2008) or more fatigue resistant type I

272 muscle fibres in women (Hunter, 2014). However, future research is needed to address this issue.

273 These novel findings come with great practical application. Sport scientists and practitioners can

274 now focus their research on how to optimize men marathon pacing,to be similar to women's or

275 half-marathoners i.e. with less variability (or possibly to utilise negative pacing profile).

\section{$276 \quad$ Limitations}

277 One of the limitations of this study is the lack of additional aspects that could influence pacing, 278 such as previous training routine, running experience or personal characteristics. Moreover, this 279 study hasanalyzed pacing profiles in marathon and half-marathon races in only oneevent (i.e. 280 “2017 Vienna City Marathon”). However, 45\% of all 2017 Vienna City Marathon participants 281 were foreign runners, and, therefore, we can exclude the factor of only one nation running this 282 event. Nevertheless, further examination of pacing in half-marathon is needed, since pacing can 283 vary, depends of the race profile, weather conditions or altitude.

\section{Conclusions}

285 In summary, the pacing in half-marathon was more even than in marathon. The more even 286 pacing in women previously observed in marathon races was verified in half-marathon, too.

287 However, the sex difference in pacing was smaller in half-marathon than in marathon. Since both 288 elite and recreational men and women runners participate in marathon and half-marathon, sport 
289 practitioners would have great benefit from these results, since they could establish sex based 290 personalized race strategies and training programs. 


\section{References}

292 Abbiss, C. R., \& Laursen, P. B. (2008).Describing and understanding pacing strategies during 293 athletic competition.Sports Medicine, 38(3), 239-252.

294 Angus, S. D. (2014). Did recent world record marathon runners employ optimal pacing 295 strategies?.Journal of Sports Sciences, 32(1), 31-45.

296 Buman, M. P., Brewer, B. W., Cornelius, A. E., Van Raalte, J. L., \&Petitpas, A. J. (2008).

297 Hitting the wall in the marathon: Phenomenological characteristics and associations with 298 expectancy, gender, and running history.Psychology of Sport and Exercise, 9(2), 177-190.

299 Cohen, J. (1988). Statistical power analysis for the behavioral sciences.Hillsdale, NJ: Lawrence 300 Erlbaum Associates.

301 Coyle, E. F. (2007). Physiological regulation of marathon performance.Sports Medicine, 37(4-5), $302 \quad 306-311$.

303 Deaner, R. O., Carter, R. E., Joyner, M. J., \& Hunter, S. K. (2015). Men are more likely than 304 women to slow in the marathon. Medicine and Science in Sports and Exercise, 47(3), 607.

305 De Koning, J. J., Foster, C., Bakkum, A., Kloppenburg, S., Thiel, C., Joseph, T., ...\&Porcari, J. 306 P. (2011). Regulation of pacing strategy during athletic competition.PloSOne, 6(1), e15863.

307 Hanley, B. (2015). Pacing profiles and pack running at the IAAF World Half Marathon 308 Championships.Journal of Sports Sciences, 33(11), 1189-1195.

309 Hoffman, M. D. (2014). Pacing by winners of a 161-km mountain ultramarathon.International 310 Journal of Sports Physiology and Performance, 9(6), 1054-1056. 
311 Hunter, S. K. (2014). Sex differences in human fatigability: mechanisms and insight to

312 physiological responses. ActaPhysiologica, 210(4), 768-789.

313 Knechtle, B., Nikolaidis, P. T., Onywera, V. O., Zingg, M. A., Rosemann, T., \& Rüst, C. A.

314 (2016). Male and female Ethiopian and Kenyan runners are the fastest and the youngest in both 315 half and full marathon. SpringerPlus, 5(1), 223.

316 Knechtle, B., \& Nikolaidis, P. T. (2018). Sex-and age-related differences in half-marathon

317 performance and competitiveness in the world's largest half-marathon-the Göteborgs Varvet.

318 Research in Sports Medicine, 26(1), 75-85.

319 Knechtle, B., Käch, I., Rosemann, T., \& Nikolaidis, P. T. (2019). The effect of sex, age and 320 performance level on pacing of Ironman triathletes. Research in Sports Medicine, 27(1), 99-111.

321 Lambert, M. I., Dugas, J. P., Kirkman, M. C., Mokone, G. G., \& Waldeck, M. R. (2004).

322 Changes in running speeds in a $100 \mathrm{~km}$ ultra-marathon race.Journal of Sports Science 323 \&Medicine, 3(3), 167.

324 March, D. S., Vanderburgh, P. M., Titlebaum, P. J., \& Hoops, M. L. (2011). Age, sex, and finish 325 time as determinants of pacing in the marathon. The Journal of Strength \& Conditioning 326 Research, 25(2), 386-391.

327 Millet, G. Y. (2011). Can neuromuscular fatigue explain running strategies and performance in 328 ultra-marathons? Sports Medicine, 41(6), 489-506.

329 Nikolaidis, P. T., \& Knechtle, B. (2017).Effect of age and performance on pacing of marathon 330 runners.Open Access Journal of Sports Medicine, 21(8), 171-180. 
331 Nikolaidis, P. T., Rosemann, T., \& Knechtle, B. (2018). Sex Differences in the Age of Peak

332 Marathon Race Time.The Chinese Journal of Physiology, 61.

333 Nikolaidis, P. T., \& Knechtle, B. (2018).Pacing in age group marathoners in the "New York City

334 Marathon".Research in Sports Medicine, 26(1), 86-99.

335 Nikolaidis, P. T., Ćuk, I., \& Knechtle, B. (2019).Pacing of Women and Men in Half-Marathon

336 and Marathon Races.Medicina (Kaunas), 55(1), E-pub.

337 Ogles, B. M., \& Masters, K. S. (2003). A typology of marathon runners based on cluster analysis 338 of motivations. Journal of Sport Behaviour, 26(1), 69-85.

339 Roelands, B., de Koning, J., Foster, C., Hettinga, F., \&Meeusen, R. (2013).Neurophysiological

340 determinants of theoretical concepts and mechanisms involved in pacing.Sports Medicine,43(5), $341 \quad 301-311$.

342 Roepstorff, C., Steffensen, C. H., Madsen, M., Stallknecht, B., Kanstrup, I. L., Richter, E. A., \& 343 Kiens, B. (2002). Gender differences in substrate utilization during submaximal exercise in 344 endurance-trained subjects.American Journal of Physiology-Endocrinology And Metabolism, $345 \quad 282(2), 435-447$.

346 Santos-Lozano, A., Collado, P. S., Foster, C., Lucia, A., \&Garatachea, N. (2014). Influence of 347 sex and level on marathon pacing strategy. Insights from the New York City race.International $348 \quad$ Journal of Sports Medicine, 35(11), 933-938.

349 Tarnopolsky, M. A. (2008). Sex differences in exercise metabolism and the role of 17-beta 350 estradiol.Medicine and Science in Sports and Exercise, 40(4), 648-654. 
351 Young, B. W. (2007). Perspectives on coaching pace skill in distance running. International 352 Journal of Sports Science \& Coaching, 2(3), 211-216. 
354 Table 1. Segments and race speed for men and women, marathon and half marathon runners

\begin{tabular}{|c|c|c|c|c|c|c|c|}
\hline & & $\begin{array}{c}\text { Segment } \\
1 \text { speed } \\
(\mathrm{m} / \mathrm{s})\end{array}$ & $\begin{array}{c}\text { Segment } \\
2 \text { speed } \\
(\mathrm{m} / \mathrm{s})\end{array}$ & $\begin{array}{c}\text { Segment } \\
3 \text { speed } \\
(\mathrm{m} / \mathrm{s})\end{array}$ & $\begin{array}{c}\text { Segment } \\
4 \text { speed } \\
(\mathrm{m} / \mathrm{s})\end{array}$ & $\begin{array}{c}\text { Segment } \\
5 \text { speed } \\
(\mathrm{m} / \mathrm{s})\end{array}$ & $\begin{array}{l}\text { Average } \\
\text { race speed } \\
\quad(\mathrm{m} / \mathrm{s})\end{array}$ \\
\hline \multirow{4}{*}{$\begin{array}{c}\text { Men } \\
42.2 \mathrm{~km} \\
\mathrm{~N}=4807\end{array}$} & Mean & 3.210 & 3.152 & 3.116 & 2.856 & 2.880 & 3.059 \\
\hline & $\mathrm{SD}$ & 0.450 & 0.453 & 0.483 & 0.526 & 0.490 & 0.462 \\
\hline & Min & 2.028 & 1.916 & 1.716 & 1.521 & 1.565 & 1.931 \\
\hline & Max & 5.522 & 5.420 & 5.429 & 5.495 & 5.474 & 5.466 \\
\hline \multirow{4}{*}{$\begin{array}{l}\text { Women } \\
42.2 \mathrm{~km} \\
\mathrm{~N}=1278\end{array}$} & Mean & 2.923 & 2.854 & 2.836 & 2.663 & 2.731 & 2.807 \\
\hline & $\mathrm{SD}$ & 0.362 & 0.373 & 0.397 & 0.418 & 0.390 & 0.376 \\
\hline & Min & 2.082 & 1.986 & 1.749 & 1.549 & 1.421 & 1.939 \\
\hline & Max & 4.808 & 4.866 & 4.978 & 4.819 & 4.545 & 4.841 \\
\hline \multirow{4}{*}{$\begin{array}{c}\text { Men } \\
21.1 \mathrm{~km} \\
\mathrm{~N}=7624\end{array}$} & Mean & 3.152 & 3.137 & 3.118 & 2.972 & 3.025 & 3.100 \\
\hline & $\mathrm{SD}$ & 0.449 & 0.437 & 0.457 & 0.495 & 0.496 & 0.453 \\
\hline & Min & 2.010 & 1.814 & 1.698 & 1.605 & 1.488 & 1.808 \\
\hline & Max & 5.149 & 4.878 & 4.946 & 4.990 & 4.951 & 4.968 \\
\hline \multirow{4}{*}{$\begin{array}{l}\text { Women } \\
21.1 \mathrm{~km} \\
\mathrm{~N}=3816\end{array}$} & Mean & 2.857 & 2.838 & 2.809 & 2.680 & 2.752 & 2.803 \\
\hline & SD & 0.322 & 0.327 & 0.351 & 0.376 & 0.378 & 0.338 \\
\hline & Min & 1.980 & 1.857 & 1.599 & 1.464 & 1.412 & 1.760 \\
\hline & Max & 4.878 & 4.744 & 4.730 & 4.562 & 4.425 & 4.706 \\
\hline
\end{tabular}




\section{Figure captions}

356

357 Figure 1. Average changes of speed in every race segment, calculated as a percent change of the 358 mean race time in marathon and half-marathon. Error bars present standard deviation.

359 Figure 2. Average changes of speed in every race segment, calculated as a percent change of the 360 mean race time in marathon and half-marathonin women and men.Error bars present standard 361 deviation.

362 Figure 3. Absolute average changes of speed in marathon and half-marathon in women and 363 men.Error bars present standard deviation. $* * p<0.01 ; * \mathrm{p}<0.05 ; \# \# \mathrm{p}<0.01$. 
$375 \quad$ Figure 1

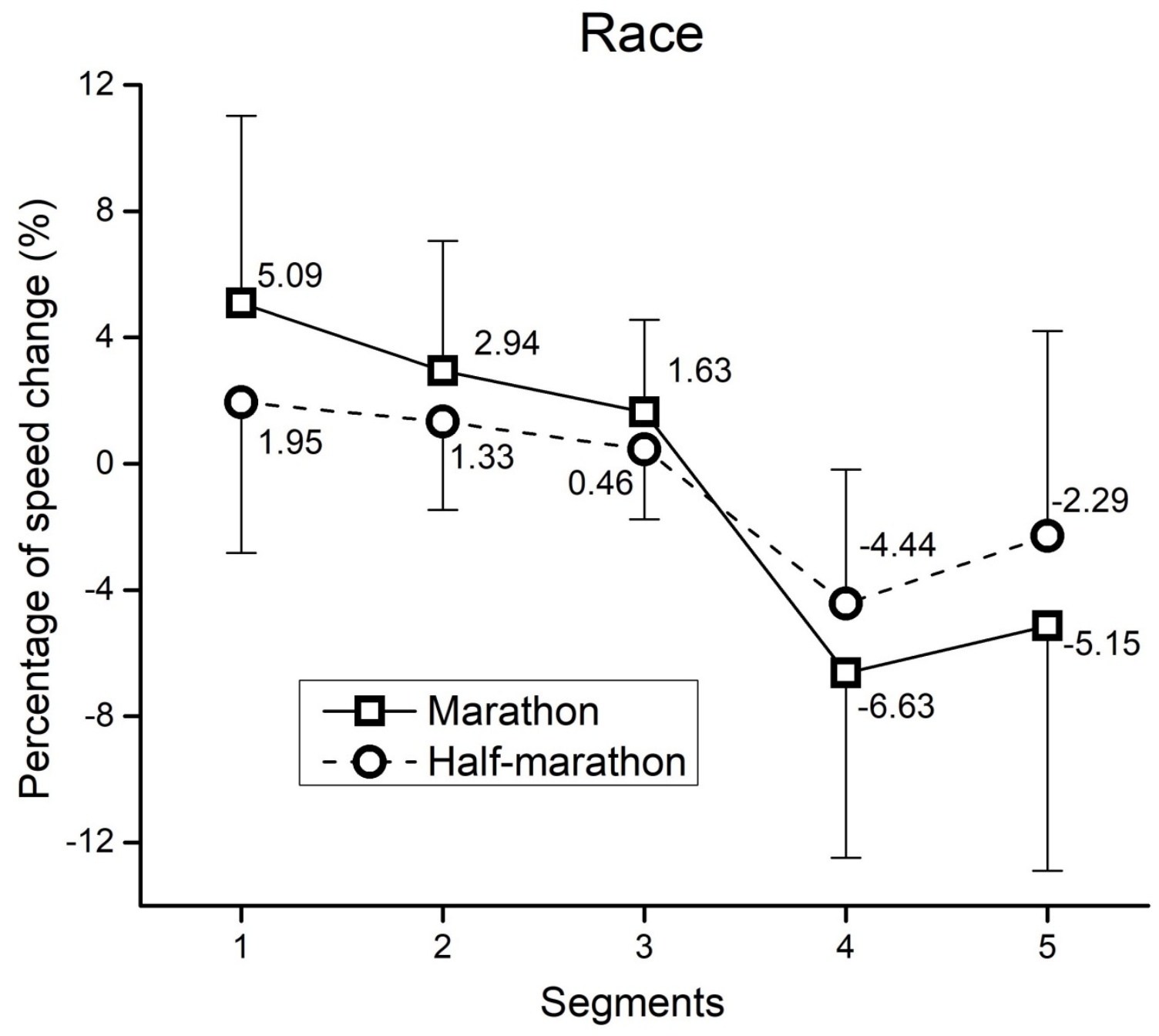


$377 \quad$ Figure 2
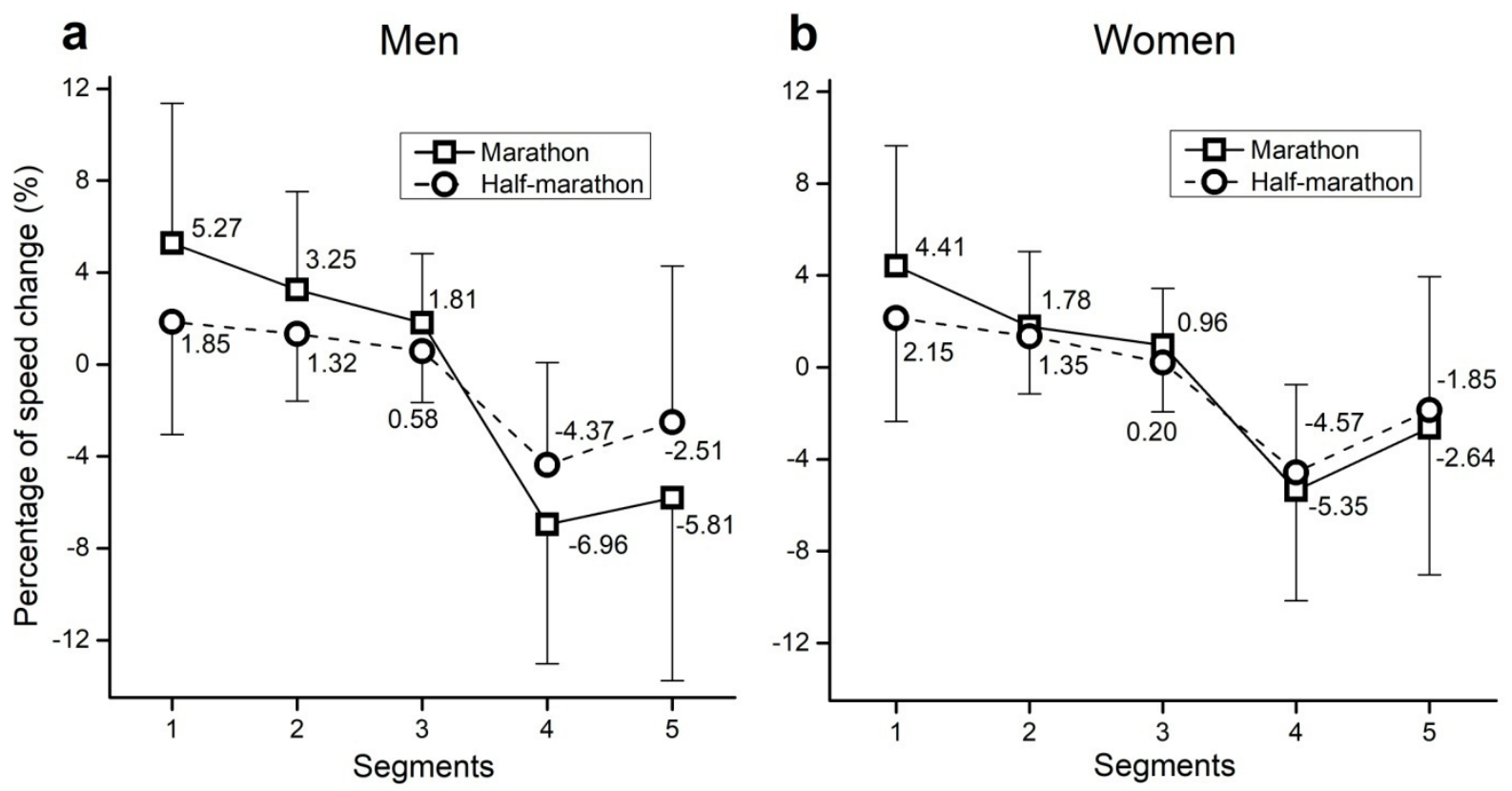


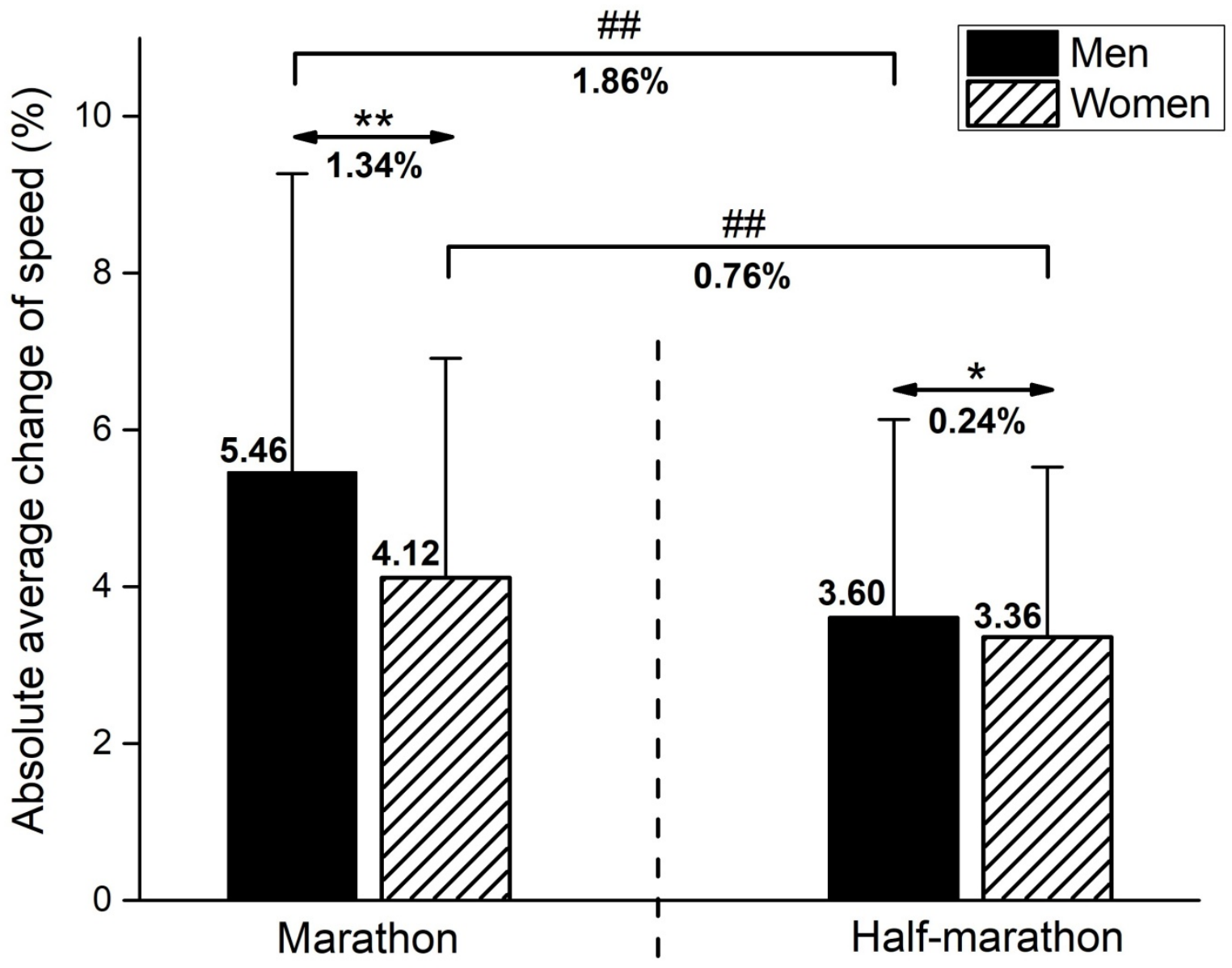

